\title{
Perspectivas teóricas sobre medicina e profissão médica: uma proposta de enfoque antropológico*
}

\author{
Theoretical perspectives on medicine and the medical profession: \\ an anthropological approach
}

\author{
Marcos de Souza Queiroz**
}

\begin{abstract}
QUEIROZ, M. de S. Perspectivas teóricas sobre medicina e profissão médica: uma proposta de enfoque antropológico. Rev. Saúde públ., S.Paulo, 25: 318-25, 1991. Estudou-se teoricamente o campo da medicina e da profissão médica sob o ponto de vista das ciências sociais. Foram focalizadas as obras mais representativas que abordam este assunto. A análise aponta o positivismo conservador e o marxismo ortodoxo como os principais obstáculos para o avanço deste campo de estudos. Sugere-se a introdução do conceito de cultura e do método antropológico de investigação para superar alguns dos principais entraves e contradições que paralisam o seu progresso.
\end{abstract}

Descritores: Medicina. Médicos. Antropologia cultural.

\section{Introdução}

O presente trabalho tem por objetivo explorar alguns aspectos teóricos sobre a medicina e a profissão médica, refletindo, ao mesmo tempo, sobre as tendências e perspectivas de pesquisas nesta área. Pretende-se, com isso, contribuir para o desenvolvimento de um campo de estudos que apenas recentemente tem despertado algum interesse entre pesquisadores brasileiros. Trata-se, sem dúvida, de um âmbito complexo que, para avançar e se consolidar dentro das ciências sociais, além de levantamento de dados e pesquisas empíricas adicionais, exigirá uma considerável concentração de esforços para resolver suas principais questões de ordem teórica.

Entre as várias razões que explicam porque esta área de estudo não tem merecido muita atenção por parte das ciências sociais, é necessário destacar dois motivos fundamentais, quais sejam, a postura marxista ortodoxa de que o campo das pro-

\footnotetext{
* Parte do projeto de pesquisa "Unidades Básicas de Serviço de Saúde: disponibilidade tecnológica, processo de trabalho e recursos humanos em Campinas" desenvolvido junto ao Núcleo de Estudos de Políticas Públicas (NEPP) da UNICAMP; financiado pelo Ministério da Saúde e pelo Fundo de Apoio à Pesquisa da UNICAMP. * Núcleo de Estudos em Políticas Públicas da Universidade Estadual de Campinas
}

$\begin{array}{ll}\text { Separatas/Reprints: } & \text { M. de S. Queiroz - Caixa Postal } 6166- \\ & \text { 13081-Campinas, SP, Brasil. }\end{array}$

Publicação financiada pela FAPESP. Processo 90/4602-1. fissões é secundário dentro da estrutura social e da dialética que a movimenta, e a postura positivista conservadora de que a divisão de trabalho em saúde (ou em qualquer outra área produtiva) é um processo natural, no qual o saber e o domínio tecnológico tendem a se revelar nas hierarquias ocupacionais existentes no processo produtivo.

De uma certa forma, estas duas posturas contribuíram para que esse campo de estudos fosse observado como uma área menor, dependente de causas mais fundamentais dentro da estrutura social. Pretendemos propor no presente artigo que o conceito de cultura (praticamente ausente na maioria dos estudos empreendidos nesta área) pode resolver muitos de seus problemas e contradições, além de restaurar a sua condição de campo legítimo e importante de atenção acadêmica.

\section{A Profissão Médica: Uma Revisão Bibliográfica Seletiva}

O estudo de profissões (termo usado no sentido de ocupações com alto nível de treinamento e autonomia) pelas ciências sociais mereceu atenção principalmente da tradição Durkheimiana, uma vez que tanto Marx como Weber não chegaram, por diferentes motivos, a prestar muito atenção nesse âmbito.

Para Marx ${ }^{3184}$ (1969), as profissões eram consideradas de caráter secundário e derivativo por serem vistas como improdutivas. Esta postura influenciou toda uma linha de pesquisa que procurava se ater, de um modo ortodoxo, aos 
princípios básicos do pensamento marxista, como será comentado adiante. O resultado foi um desinteresse marcante de pesquisadores influenciados por esta postura teórica por este assunto.

Para Weber ${ }^{24}(1968)$, as profissoes foram incorporadas em sua perspectiva de classe social e dimensionalizadas a partir de um mercado de competência. Nessa perspectiva, a sua formação e o seu desenvolvimento foram vistos sob o prisma dos tipos ideais tradicional, carismático e burocrático, sem chegar a propor e a despertar um interesse específico. Em várias ocasiōes, este autor mostrou apreensão e ceticismo quanto ao rumo inexoravelmente burocrático que tomavam as instituições modernas em geral, inclusive as profissões.

Para Durkheim ${ }^{4}$ (1957), em contraste, as profissões eram vistas como meios importantes que permitem regulação e integração nas sociedades modernas caracterizadas pela solidariedade orgânica, funcionando, assim, como uma compensação ao excessivo individualismo. Esta proposta teve continuidade e suporte na corrente teórica funcionalista, principalmente na sociologia norteamericana.

Parsons $^{18,19}$ (1964, 1968), por exemplo, acentuou a funcionalidade das profissões para a manutenção da ordem social, sendo por isso vista como um aspecto positivo de modernização, $\mathrm{cm}$ contraste com a perspectiva sombria de Weber. Um aspecto importante da produção desse autor refere-se à idéia de papéis sociais. Nesse sentido, existe não só um papel de médico, que cada profissional tenta representar da melhor maneira possivel, como o de doente que, muitas vezes, o indivíduo tenta evitar, uma vez que ele implica restrições à sua liberdade. Ao se comportar de um modo desviante, o doente sofre pressões sociais no sentido de se conformar com o papel apropriado correspondente, transferindo temporariamente a autonomia de suas decisões à instituição médica legitimamente reconhecida como a única adequada para tratar de sua saúde.

A produção científica influenciada por Parsons é numerosa principalmente nos Estados Unidos. Nela, em geral, predomina a perspectiva positivista, muitas vezes uma simples máscara ideológica da ordem social dominante, percebida como uma dimensão natural, na qual o desvio e o conflito tendem a ser encarados como sinais patológicos. Este esquema um tanto rígido e inflexível, além de não admitir o conflito, não percebe que em qualquer ordem social há uma disponibilidade de papéis sociais contraditórios igualmente legítimos de acordo com o contexto ou a situação $\mathrm{cm}$ que são usados e manipulados por indivíduos ou grupo sociais.

Friedson ${ }^{6,7}(1970)$, desenvolveu uma linha bastante crítica da perspectiva funcionalista tradicio- nal, principalmente de Parsons, ao assumir que o surgimento e a manutenção das profissões estavam relacionados com mecanismos de controle e de poder exercidos pelos interesses dominantes da sociedade mais ampla. Ao analisar a profissão médi$\mathrm{ca}$, esse autor parte do pressuposto de que o que cada um dos profissionais diz de si mesmo não pode ser tomado como realidade objetiva como fizera Parsons, mas tão somente como matériaprima de investigação. Além disso, a fonte do poder e do grande prestígio social usufruído por esta profissão passou a ser localizada, não só na importância do saber que ela domina e controla, como também no contexto social mais amplo ao nível do Estado que, por vários motivos, principalmente de autopreservação, tem interesse na manutenção e difusão desse tipo de instituição.

Para Friedson ${ }^{6,7}$, uma profissão distingue-se em relação a outras ocupações menores no que se refere à autonomia organizada e legitimada em seu poder. Tal autonomia confere à profissão um monopólio ocupacional que assegura uma posição de dominância no interior do processo de divisão de trabalho. Esta autonomia é, para ele, baseada em dois princípios fundamentais: o conhecimento esotérico reconhecido e protegido pelo Estado e o apoio das elites.

Apesar de procurar as causas da organização médica na estrutura social, Friedson ${ }^{6,7}$ não chega a tocar em questões cruciais, tais como, a natureza das elites por ele mencionada, o relacionamento da profissão com o Estado, e os interesses econômicos, sociais e políticos que sustentam o apoio dado pelo Estado. Este lapso deixou uma margem generosa para a crítica desenvolvida principalmente por autores marxistas. A grande virtude de Friedson foi a sua descrição e análise interna à profissão médica, dando contribuição decisiva para a dimensionalização desse campo de estudos.

A produção marxista na área da medicina e saúde é importante principalmente pelo seu esforço de prover uma teoria que estabeleça uma conexão consistente desta área com a sociedade mais ampla. Com este propósito, tanto Navarro ${ }^{16,17}$ $(1976,1984)$ como Wright ${ }^{27}$ (1980) situam a profíssão médica dentro da estrutura de classe da sociedade capitalista. Ao enfatizar este ponto, esses autores criticam vários estudos realizados sobre a divisão do trabalho na área da saúde que, por não se preocuparcm com esse aspecto, confundem ocupaçðes com classes.

Nesse sentido, Wright ${ }^{27}$ define ocupação como uma posição dentro das relações técnicas de produção e classe como o conjunto de relações sociais de produção estabelecidas com a outra classe social. Dentro do esquema clássico do marxismo, cada modo de produção gera duas classes funda- 
mentais, uma dominante e outra dominada política, econômica e culturalmente. A classe dominante detém a posse dos meios de produção, controlando todo o processo produtivo, enquanto a classe dominada só conta com a sua força de trabalho que é vendida no mercado de acordo com 0 interesse básico da classe dominante, qual seja, a exploração do trabalho através da mais-valia. Uma sociedade concreta, no entanto, envolve um número maior do que estas duas classes, à medida que ela é composta de vários modos de produção secundários. Numa formação social capitalista, a burguesia e o proletariado constituem as duas classes fundamentais, embora outras, compondo o setor intermediário, sejam também encontradas.

Johnson ${ }^{11}$ (1977), enfatiza que no capitalismo monopolista o capital é transformado em processo de trabalho através de mecanismos complexos de controle produtivo. Os agentes que preenchem as funções da acumulação de capital podem ser identificados como parte da nova classe média, à medida que ela expressa tanto a função e realização do capital como a de trabalho. As várias ocupações na área da saúde, hierarquicamente subordinadas aos médicos, têm pouca autonomia na performance de seu trabalho e podem ser identificadas como parte da classe proletária, independentemente da condição de ser produtiva ou não. Este autor analisa ainda a reprodução do sistema produtivo nas esferas política e ideológica empreendida principalmente pelo Estado e pelas "profissões" (envolvendo as áreas da saúde, educação, ciência e tecnologia). Portanto, a reprodução do sistema produtivo, principalmente no que diz respeito à reprodução da força de trabalho, provê a base teórica para a autonomia da medicina e seu papel dominante no processo de trabalho na área da saúde.

Willis ${ }^{25}$ (1983) enfatiza esse ponto, salientando que a base fundamental para a autonomia da profissão médica deve ser explicada basicamente pelo relacionamento da profissão médica com o Estado. Nesse caso, o papel do médico resume-se em ser capaz de estruturar e organizar o processo de trabalho na saúde, sendo que este direito corresponde à contrapartida concedida pelo Estado para que a medicina continue exercendo o seu importante papel no controle da força de trabalho e na reprodução de valores fundamentais para a manutenção do sistema produtivo como, por exemplo, a visão individualista da doença e da cura e as soluçðes baseadas em tecnologia industrial. Portanto, a profissão médica assume, na visão de Willis, um monopólio de geração de definiçðes, de práticas e de serviços à medida que estes coincidem com o interesse oficial. A medicina torna-se, assim, uma instituição importante de controle social.

Analisando as ocupações e profissões diante da organização capitalista de produção, Braverman ${ }^{1}$ (1974) conclui que a perda da autonomia no processo produtivo é uma tendência que atinge todas as ocupações e profissões, inclusive a do médico. Segundo o seu ponto de vista, haveria uma tendência histórica implacável segundo a qual a autonomia e a dignidade das profissões seriam perdidas e a degradação viria à medida que o capitalismo se desenvolve em estágios mais complexos $\mathrm{e}$ sofisticados de dominação.

Consistente com esta postura, Donnangelo ${ }^{3}$ (1975) interpreta o crescente assalariamento dos médicos como uma consequiência inevitável da passagem do padrão "artesanal" para novas modalidades de organização da produção, onde o aumento de produtividade e a diversificação dos meios de trabalho geram um quadro organizacional complexo e burocratizado em que o produtor de serviços (o médico) tende a perder o controle do processo e a posse dos meios de produção.

Outros autores, que deram uma contribuição importante para o desenvolvimento deste campo de estudos, tais como Starr $^{23}$ (1982) e Gonçalves ${ }^{8}$ (1985) serão comentados adiante oportunamente.

\section{A Critica da Postura Positivista}

De um modo geral, a concepção positivista da ciência moderna confere uma preponderância explícita ao método enquanto modelo lógicoconceptual que enquadra e seleciona os dados no interior de seus próprios limites. Nesse sentido, como muito bem apontou Marcuse ${ }^{13}$ (1969), o positivismo caracteriza-se por conceber um tipo de razão subjetiva, formal e instrumental, cujo único critério de verdade é seu valor operativo, ou seja, seu papel na dominação do homem e da natureza.

$\mathrm{Se}$, nas ciências sociais, o positivismo não tem resistido aos seus críticos, sucumbindo diante de metodologias mais modernas e sofisticadas, em vários outros campos científicos, particularmente nas ciências naturais e administrativas (que têm influência importante nas ciências da saúde), ele tem subsistido a ponto de ainda coincidir com o seu paradigma dominante*.

* O termo paradigma é tomado no sentido empregado por $\mathrm{Kuhn}^{12}$ (1975), ou seja, um mapa que governa a percepção do cientista de tal modo que permite dimensionar apenas os objetos compatíveis com ele. Desse modo, a ciência normal pode apenas estender o seu paradigma dominante a novas áreas da realidade, referendando o já sabido ao invés de produzir novos conhecimentos. O paradigma dominante de um campo científico é profundamente influenciado, não só pelo seu desenvolvimento interno, mas pelas influências externas provenientes da sociedade mais ampla em que se insere. 
O paradigma positivo-mecanicista dominante na medicina tende a não reconhecer o papel da sociedade, da cultura, da comunidade científica e da própria história na determinação de seu objeto de conhecimento e da maneira abordá-lo. Pressupõe-se, assim, que 0 ato terapêutico possa ser explicado exclusivamente pela intervenção química ou física nas diferentes partes e estruturas do organismo humano no sentido de eliminar a doença, percebida, em grande medida, pela agressão monocasual externa de um agente patológico.

$O$ aspecto organizacional da medicina, em consonância com esse paradigma, é considerado uma consequiência natural do desenvolvimento e da complexidade de seu saber e do nível tecnológico correspondente. Nesse esquema, a divisão de trabalho deve ocorrer naturalmente como resultado desses fatores, enquanto o processo de trabalho deve significar administração de recursos humanos no sentido de adequá-los às necessidades técnicas de produção.

Nesse contexto, a hierarquização das funções é vista como uma questão meramente técnica, sem qualquer resíduo político. Toda a questão se resume na interpretação de que a medicina domina a divisão de trabalho na saúde porque ela controla o conhecimento sobre o qual depende o processo de cura. Portanto, a divisão de trabalho nessa área não é encarada como problema, mas como a expressão da relação de saber numa forma naturalmente hierarquizada. Nesse sentido, qualquer tipo de conflito dentro de um campo profissional é configurado como sintoma de patologia social ou administrativa.

No entanto, dois fatores fundamentais têm recentemente contribuído para abalar, na área da saúde, os alicerces do paradigma positivomecanicista. O primeiro e principal deles diz respeito à deficiência desse paradigma em conceptualizar os problemas modernos da saúde humana. Como tem mostrado estudos sérios sobre o assunto, condições ambientais, sócio-econômicas e culturais revelam-se com importância incomparavelmente maior para a saúde de uma população do que condições relativas à intervenção médica biológica individual (McKeown $\left.{ }^{15}, 1979\right)$. Existem também fartos indícios de que, a partir de um certo ponto, o aumento do nível de atividades médicas numa sociedade não corresponde a um aumento do nível de saúde da população (Ehrenreich ${ }^{5}$, 1978; Powles 21, 1974).

O segundo fator que tem contribuído para abalar o paradigma positivo-mecanicista diz respeito aos custos crescentes que esse tipo de medicina (inevitavelmente baseado em alta tecnologia), acarreta. Este fator torna-o incompativel com o ideal de democratização da oferta de serviços médicos, princi- palmente em países em desenvolvimento com escassez crônica de recursos financeiros.

\section{A Crítica da Postura Marxista}

Seria, sem dúvida, injusto considerar generalizadamente a postura marxista como um obstáculo ao desenvolvimento do campo de estudos relacionados com a medicina, a saúde e a profissão médica, mesmo porque uma parte significativa da produção científica nessa área tem sido realizada a partir deste ponto de vista teórico. Além disso, existe um marxismo mais aberto que mostra maior flexibilidade conceptual, permitindo, com isso, uma abordagem mais livre e, sem dúvida, mais fértil. No entanto, como esperamos deixar claro, sempre quando a teoria e os conceitos do marxismo ortodoxo se tornam rígidos e formatórios, eles efetivamente passam a constituir obstáculo para o desenvolvimento e consolidação deste campo de estudos.

De um modo geral, este último tipo de marxismo tem se preocupado com a problemática dos campos institucionalizados do saber e das profissões em geral apenas com o intuito de reduzilos à condição de expressão secundária de componentes estruturais mais amplos e profundos da sociedade. Dessa maneira, a medicina e a profissão médica são observadas como um espelho que reflete (sem contribuir para promover) o desenvolvimento do capitalismo e a relação específica que esse modo de produção estabelece com as classes sociais.

Sob esse ponto de vista, o estudo da profissão médica (que, de um modo geral, se posiciona em estreita aliança com a classe dominante), não chega a merecer muito interesse, basicamente porque esta profissão é considerada uma corporação que, sob o ponto de vista sociológico, além de não apresentar problemas e soluções teóricos significativos, está fadada, enquanto parte da classe capitalista dominante, a ser superada pela história.

A classe dominada, por sua vez, sempre merece ser focalizada, pois, ao tentar resistir à sua dominação e reivindicar novos interesses e novas formas de organização e distribuição de recursos, representa inevilavelmente o futuro. No entanto, como não se considera a medicina e a área de saúde como campo produtivo (no sentido de gerar mais-valia e acumulação de capital), a classe dominada em seu interior não é considerada estratégica na luta revolucionária e, por isso, não desperta muito interesse para estudo.

No entanto, embora, de um modo geral, tenha sido essa a tônica entre autores marxistas em geral, pode-se observar em alguns deles uma maior 
abertura, como, por exemplo, no caso de Willis ${ }^{25}$ (1983) que, sem abdicar dos princípios básicos dessa corrente, valoriza os aspectos culturais que envolvem o processo de trabalho e a organização dos serviços de saúde. Este autor entende, como nós também entendemos, que o capitalismo é compatível com muitos sistemas de cuidados médicos divergentes entre si e, por isso, é uma força explicativa muito genérica e insuficiente para captar a forma concreta assumida por uma determinada medicina num determinado contexto social.

No Brasil, Gonçalves ${ }^{8}$ (1986), ao realizar um estudo sobre os recursos disponíveis nos serviços básicos de saúde, rompe com a dicotomia infraestrutura e superestrutura, ao considerar não só a organização de trabalho como o saber próprio das diferentes categorias profissionais como tecnologias análogas aos instrumentos materiais de produção de serviço. Esse aspecto, que encontra em Gramsci ${ }^{9}$ uma fonte fértil de inspiração é, no nosso entender, dos mais importantes do ponto de vista teórico. Voltaremos a discorrer sobre este problema adiante.

Excluindo algumas poucas exceções, no entanto, um ponto comum partilhado, em maior ou menor grau, pela maioria dos autores marxistas, é que as necessidades do sistema produtivo determinam o desenvolvimento de qualquer aspecto institucional dentro deste sistema. Esta é uma postura que, em suas nuances mais radicais, corre o risco de se revestir de um totalitarismo que oferece pouca ou nenhuma autonomia às suas partes, conduzindo a análise a um determinismo pobre, estreito e sem profundidade.

De acordo com esta perspectiva, se a medicina científica prevaleceu historicamente sobre outras formas alternativas, foi porque ela seria mais funcional ao sistema capitalista dominante. Este, é importante lembrar, significa o ponto mais alto atingido pela história antes de entrar em crise e ser superado pelo socialismo. Da mesma forma, se o investimento em medicina curativa mostra-se maior do que o em medicina preventiva seria porque na primeira o lucro é maior e sua manifestação mais conforme ao "ethos" individualista do sistema capitalista dominante. Nessa visão, a medicina curativa é percebida como resultante de uma forma de organização irracional onde predomina uma visão individualista do lucro. Esse sistema entraria em colisão com as necessidades colctivas da população, as quais somente um Estado centralizado e uma economia socialista planificada poderiam satisfazer.

No entanto, existem interpretações convincentes que estimulam a indagação se realmente este argumento teria condições de resistir a uma investigação mais apurada. Dados preliminares in- dicam claramente que ela não teria condições de resistir a um confronto com os fatos. É, por exemplo, difícil sustentar porque o capitalismo haveria de beneficiar a medicina curativa ao invés da preventiva, uma vez que esta última é, indiscutivelmente, um melhor investimento econômico do que a primeira. A expansão do comércio, a crescente coordenação das atividades econômicas e as necessidades cada vez mais complexas das grandes corporações criaram, de fato, uma demanda para a saúde pública que o capitalismo foi capaz de satisfazer justamente onde ele se manifesta com maior vigor (Starr $\left.{ }^{23}, 1982\right)$.

É um fato incontestável, no entanto, que a medicina preventiva representa, pelo menos no âmbito ideológico, um paradigma que se opõe em muitos aspectos ao da medicina curativa. A idéia de uma medicina coletiva procurando doenças em determinantes sociais mais amplos e a saúde no controle ambiental e educação comunitária contrapõe-se ao paradigma positivo-mecanicista que toma como universo de saúde e doença o corpo humano considerado individualmente. $O$ que parece simplista e artificial, no entanto, é atrelar automaticamente, sem respeito ao contexto e às condições históricas, um desses paradigmas a um determinado modo de produção.

O mesmo pode-se dizer quanto à tese de Braverman ${ }^{1}$ de que as profissões tendem a se degradar e a se degenerar diante do desenvolvimento do modo capitalista de produção. A persistência da autonomia da profissão médica é um caso que desafia tal postura. Como mostra Campos² (1988), o processo de capitalização da medicina, ao mesmo tempo que reduziu o trabalho puramente liberal à condição de forma residual, recriou condições para a expansão do assalariamento e, sobretudo, do exercício autônomo, sendo esta última a forma predominante. Neste sentido, a realidade empírica mostra neste caso que não há contradição entre o trabalho autônomo e o processo de acumulação de capital. Portanto, a previsão da inevitabilidade do processo de perda da autonomia pelos vários pequenos produtores de bens e serviços não ocorreu e nada indica que possa vir a ocorrer no caso da medicina.

Este caso mostra muito bem que uma ótica teórica pode, em certos contextos, obscurecer mais do que esclarecer um determinado aspecto da realidade. Isso significa que confiar irrestritamente numa teoria pode ser bastante perigoso, à medida que essa atitude concorre para que ela deixe de ser um meio ou um instrumento de apreensão da realidade e adquira vida própria fazendo com que a realidade se adapte aos scus princípios.

Um outro aspecto crucial da crítica ao marxismo na área da medicina c saúde diz respeito à des- 
consideração pela noção de cultura. Navarro ${ }^{16}$ (1976), por exemplo, ao analisar a organização médica em vários países desenvolvidos e subdesenvolvidos, focaliza o problema da profissão e do processo de trabalho sob o ponto de vista das relações gerais entre classes sociais, negligenciando o seu caráter específico no interior de um determinado campo institucional. Para este autor, todas as profissões são meros reflexos da estrutura de classe verificada na sociedade mais ampla. Consequientemente, a sua conclusão é automática e definitiva: antes de mudar a medicina para melhor, é necessário mudar a sociedade.

Nesse esquema, qualquer tentativa de revestir a medicina com um caráter mais social e humano como, por exemplo, a declaração de Alma-Ata, são observadas como sendo apenas máscaras ideológicas impostas pela burguesia para pretender manter o "status quo" e confundir a luta revolucionária (Navarro ${ }^{17}, 1984$ ). É evidente que esta concepção rígida e inflexível da teoria marxista não permite perceber a cultura como um elemento que organiza o comportamento social em vários niveis de realidade, inclusive o produtivo.

\section{A Legitimação Ideológica da Autonomia e Dominância Médica}

Nesta parte, pretendemos levantar alguns pontos sobre o processo de legitimação da medicina e da profissão médica que têm sido focalizados e dimensionalizados tanto pela postura marxista como não marxista.

A questão da ideologia do profissionalismo, que legitima a autonomia reivindicada pelos médicos, é importante nesse sentido por contribuir para reproduzir aspectos cruciais da ideologia dominante. Gramsci ${ }^{9}$, por exemplo, dentro de um marco marxista mais aberto, percebe a profissão médica como provedora de significativo suporte ideológico à base do domínio burguês no capitalismo monopolista. Segundo esse autor, os médicos devem ser considerados como intelectuais que emergem em associação com a nova classe dominante no capitalismo adiantado, "exercendo as funções subalternas de hegemonia social e governo político" (Gramsci $\left.{ }^{9}, 1971\right)$.

Habermas $^{10}$ (1972), sem mostrar nenhum compromisso com a teoria marxista, embora levando $\mathrm{cm}$ consideração a sua importância, considera que a profissão médica reproduz "a ideologia do especialista profissional", aspecto este que pode ser constatado em qualquer sociedade industrial, seja ela socialista ou capitalista. Segundo esse autor, esta idcologia enfatiza a racionalidade tecnológica e instrumental, cujo único critério de verdade é a sua efetividade e seu valor operativo no interior de um conjunto estreito de interesses industriais, burocráticos ou militares. Estes componentes ideológicos reforçam a reivindicação de que o conhecimento tecnológico é um poder benéfico, ainda que legitime desigualdade, injustiça, opressão e elitismo.

É uma questão que não levanta muitos problemas o fato da medicina realizar a mediação de importantes valores sociais que servem aos interesses sócio-econômicos, políticos e culturais dominantes. É inquestionável, nesse sentido, que ela adquire legitimidade em função de se posicionar em estreita sintonia com a sociedade e cultura hegemônicas. Em perfeita consonância com Habermas ${ }^{10}$, é possível dizer que, não obstante os avanços genuínos da medicina diante de seu próprio paradigma, a sua eficácia objetiva (que o positivismo clama existir independentemente de qualquer configuração sócio-cultural) é um aspecto secundário na sua legitimação. Pretender, nesse sentido, que a base de legitimação da medicina ou a justificação de sua lógica operacional repouse na sua eficácia no tratamento de doenças (que são vistas como entidades universais independentes de contexto cultural ou histórico) é uma reivindicação positivista ingênua $e$ ideológica incapaz de resistir a uma análise mais consistente da realidade.

$\hat{E}$, portanto, evidente que a medicina cientifica moderna apresenta, em sua forma hegemônica, um paradigma que mostra numerosas analogias com a sociedade industrial ou, na terminologia marxista, com o modo de produção que ela contribui para reproduzir. No aspecto organizacional, o grau de especialização e a complexidade da sua divisão de trabalho que ocorrem principalmente na área hospitalar hegemônica, além das tecnologias complexas que envolvem a operacionalização do ato médico, não deixam dúvidas quanto ao caráter industrial da medicina modema. A analogia do corpo com uma máquina com partes trocáveis e soluções de engenharia é um traço importante desse aspecto. Alćm de oferecer suporte à ideologia e à cultura dominantes, a prática médica efetivamente controla a força de trabalho em favor das necessidades da produção (Possas ${ }^{20}, 1981$ ).

Isso posto, no entanto, é nosso argumento sustentar que medicinas de qualidades e propósitos muito difcrentes entre si podem ser organizadas em qualquer sistema produtivo, contribuindo para oferecer serviços que variam entre favoráveis e desfavoráveis à saúde humana, chegando inclusive $a$ influenciar positiva ou negativamente o próprio nível produtivo da sociedade mais ampla. O campo da medicina apresenta, neste esquema, um grau de autonomia muito maior do que pretende o marxismo 
ortodoxo, embora, muito menor do que reivindica o positivismo clássico. Somente um estudo contextual de cada situação pode revelar a sua real posição.

\section{Comentários Finais}

A antropologia social e cultural tem se encarregado de mostrar que a dimensão cultural mostra uma esfera de abrangência muito maior do que o sentido marxista de ideologia (Sahlins ${ }^{22}, 1976$ ). A sua configuração não se adapta, de modo algum, ao que Marx entendia por superestrutura econômica e social. Em realidade, como muito bem demonstrou Worsley ${ }^{26}$ (1982), o espaço compreendido pelo termo cultura ocorre principalmente no âmbito da infra-estrutura, compondo com as forças produtivas e os meios de produção um todo indivisível.

A análise de artefatos ou maneiras de produzilos em sociedades "primitivas" mostra muito bem a impossibilidade de separar o conteúdo técnico e operacional do aspecto simbólico. A dificuldade de perceber este ponto em nossa própria sociedade é que, imersos no simbólico, não temos referência para distingui-lo. Dessa maneira, o que é, em grande medida, um aspecto cultural tende a ser percebido apenas como uma solução técnica inevitável diante do propósito a que ela serve.

Desta forma, sustentamos o ponto de que aspectos culturais influenciam ou mesmo determinam o que e como produzir no momento mesmo da produção e não numa esfera metafísica ou ideológica da realidade. Sem aceitar esse aspecto, o marxismo corre o risco de conviver com um viés evolucionista unilinear e etnocêntrico, onde o caráter mecânico e técnico da produção, despojado de qualquer simbolismo, propelido por uma vaga $\mathrm{e}$ obscura noção de progresso, agiria como o motor da história.

$\mathrm{O}$ autor marxista que mais valorizou a cultura como agente transformador ou mantenedor da sociedade foi $\mathrm{Gramsci}^{9}$, que compreendeu muito bem que sem uma transformação cultural, por mais que se desenvolvam as forças produtivas, não haverá possibilidade de revolução. Daí a ênfase que a sua obra atribui ao partido e aos intelectuais na transformação cultural de uma sociedade. A sua grande virtude é, sem dúvida, descartar completamente a possibilidade de evolução social através de forças produtivas mecânicas ou abstratas que se desenvolvem automaticamente.

Nesse sentido, sustentamos o ponto de que a dimensão cultural, principalmente a encontrada num setor importante como a prestação de serviços de saúde, contribui decisivamente tanto para a manutenção como para a transformação da sociedade.
Esta postura não diminui a importância do Estado e da relação de classes; ela apenas introduz um outro aspecto não menos importante da realidade social.

Talvez a principal virtude dessa dimensão é estimular a pesquisa de campo. Ao invés de analisar uma determinada realidade institucional, reduzindo-a a um epifenômeno de causas maiores como, por exemplo, a estrutura de classes ou a organização do Estado, ela procura, sem excluir a influência desses fatores mais abrangentes, concentrar-se no que a realidade estudada tem de especifico. Essa atitude permite, ainda, procurar $e$ encontrar, nessa mesma realidade, as condições que contribuem para sustentar o seu relacionamento com os fatores sócio-econômicos, políticos e culturais mais abrangentes. O método antropológico de análise qualitativa de pequena escala absorveu muito bem esse tipo de enfoque e, por isso, pode oferecer uma contribuição significativa para esse campo de estudo.

QUEIROZ, M.de S. [Theoretical perspectives on medicine and the medical profession: an antropological approach. Rev. Saúde públ., S.Paulo, 25: 318-25, 1991. The medical field and profession are studied from the theoretical point of view of the social sciences. The most representative works on this subject are presented. The analysis shows that conservative positivism and orthodox Marxism are the main obstacles to development in this field of study. At the same time it suggests the concept of culture and the anthropological method of research as the best means for the overcoming of some of the main contradictions which paralyse its progress.

Keywords: Medicine. Physicians. Anthropology, cultural.

\section{Referências Bibliográficas}

1. BRAVERMAN, H. Labor and monopoly capital. New York, Monthly Review Press, 1974.

2. CAMPOS, G.W. Os médicos e a política de saúde. São Paulo, Hucitec, 1988.

3. DONNANGELO, M.C.F. Medicina e sociedade. São Paulo, Ed. Pioneira, 1975.

4. DURKIIELM, E. Professional ethics and civic morals. London, Routledge \& Kegan Publ., 1957.

5. EIIRENREICH, J., ed. The cultural crisis of modern medicine. New York, Monthly Review Press, 1978. p. 1 35:Introduction.

6. FRIEDSON, E. Professional dominance. Chicago, Aldine, 1970.

7. FRIEDSON, E. Profession of medicine. New York, Dodd Mead, 1970.

8. GONÇALVES, R.B.M. Tecnologia e organização social das práticas de saúde. São Paulo, 1986. [Tese de Doutoramento - Faculdade de Medicina da USP]

9. GRAMSCI, A. Prison notebooks. New York, Intemational Publishers, 1971.

10. HABERMAS, J.. Toward a rational society. London, Heinemann, 1972.

11. JOHNSON, T. The profession in the class structure. In: Scase, R., ed. Industrial society: class, cleavage and control. London, Allen \& Unwin, 1977. p. $166-94$. 
12. KUHN, T.S. A estrutura das revoluçôes cientificas. São Paulo, Ed. Perspectiva, 1975.

13. MARCUSE, H. Razâo e evolução. Rio de Janeiro, Ed. Saga, 1969.

14. MARX, K. O Capital. London, Bums, 1969. v. 4: Theories of Surphis value.

15. MCKEOWN, T. The role of medicine. Oxford, Basil Blackwell, 1979.

16. NAVARRO, V. Medicine under capitalism. New York, Prodist, 1976.

17. NAVARRO, V. A critique of the ideologycal and political position of the Brandt Report and Alma Ata Declaration. Int. J. med. Serv., 14: 159-72, 1984.

18. PARSONS, T. The social system. New York, Free Press, 1964.

19. PARSONS, T. Professions. In:International Encyclopaedia of Social Sciences. New York, Macmillan, 1968. p. 534-46.

20. POSSAS, C. Saúde e trabalho. Rio de Janeiro, Graal, 1981.
21. POWLES, J. On the limitation of modern medicine. Med. and Man, 1 (1): 1-30, 1974.

22. SAHLINS, M. Culture and practical reason. Chicago, The University of Chicago Press, 1976.

23. STARR, P. The social transformation of American medicine. New York, Basic Books, 1982.

24.WEBER, M. The sociology of religion. London, Methuen, 1966.

25. WILLIS, E. Medical dominance. London, George Allen \& Unwin, 1983.

26. WORSLEY, P. M. Marxism and culture: the missing concept. Manchester, Engl., University of Manchester Press, 1982. (Occasional Paper $n^{\ominus} 04$ ).

27. WRIGHT, E.D. Class and occupation. Theory and Soc., 9 (1): $177-214,1980$.

Recebido para publicaçäo em 18/10/1990 Aprovado para publicaçáo em 25/3/1991 